\title{
Do possível diálogo entre Donald Schön e Tim Ingold para uma prática experimental com material
}

Dimas Bortolini Gloeden;

Celso Carnos Scaletsky

\section{resumo:}

Este artigo visa explorar a possível relação entre a ideia de experimentação exploratória sustentada por Donald Schön e a compreensão de material defendida pelo antropólogo Tim Ingold. Tais conceitos quando aproximados, parecem corresponder a uma discussão mais profunda acerca da dimensão material no design, propondo caminhos de ações relacionais, e portanto, menos preocupadas com investigações de ordem científica. Afim de investigar esse potencial, recorreu-se a um breve experimento por parte dos autores, na tentativa de melhor ilustrar as reflexões trazidas por estas abordagens. Por fim, constatou-se ser possível despertar comportamentos desconhecidos no material, através de uma prática que se mostrou valorizar a imprevisibilidade do processo de criação, bem como o caráter impermanente da matéria, aqui considerada "viva".

\section{palavras-chave:}

materiais; design; experimentação material 


\section{Introdução}

Os materiais mantém uma relação essencial com a representação das ideias que surgem a partir do processo projetual. $\mathrm{O}$ designer concebe juntamente com a utilização de métodos e tecnologias específicas, produtos que - no caso da indústria - se concretizam pelos aspectos tangíveis da matéria. Nesse sentido, o produto ou o "objeto final", segundo Dias (2009), é feito de um ou mais materiais e sua estrutura tem propriedades correspondentes ao processo de fabricação. Processo que por sua vez é ditado pela forma última do objeto, cujo resultado torna-se a expressão da combinação destes fatores.

Manzini (1993) menciona que forma, função e material são elementos que não se distanciam, sendo portanto interdependentes. Tal caráter essencialmente hilemórfico ${ }^{1}$, resume amplamente o "lócus" da indústria moderna, em que materiais foram submetidos a tratamentos rígidos sob processos otimizados de produção.

Contrário a este modelo, Tim Ingold em sua obra "Estar Vivo", apresenta uma forte crítica ao conceito abstrato de materialidade, por esta ainda sustentar uma interpretação limitada acerca dos materiais e suas transformações. Segundo o autor, aprenderíamos muitos mais "[...] envolvendo-nos diretamente com os próprios materiais, seguindo o que acontece com eles quando circulam, misturamse uns aos outros, solidificam-se e se dissolvem na formação de coisas mais ou menos duráveis" (INGOLD, 2015, p.45). Este discurso ganha ainda mais notoriedade na medida em que revela os materiais como ativos, ou seja, matérias vivas que correspondem com as forças do ambiente.

Em estudos recentes na área do design, aponta-se uma nova direção para com as relações materiais dentro dos métodos projetuais (Karana et al., 2015; Vallgårda et al., 2010). Se tratando principalmente de abordagens exploratórias, entende-se que as mesmas divergem significativamente das diretrizes técnicas, tendo os seus interesses voltados aos aspectos afetivos e experienciais. Buscam-se ideias de ações experimentais livres, a exemplo do que caracteriza uma prática de estúdio, onde o processo criativo consiste em grande parte da improvisação e envolvimento direto entre diferentes articuladores. A experimentação portanto, tem seu papel fundamental dentro das concepções de design e já fora amplamente discutida por autores como Donald Schön, a respeito primordialmente do processo de "reflexão na ação", que conduz novas experiências de fazer e pensar sobre o problema de projeto.

Ao julgarmos tal conceito como sobreposto à temática dos materiais aqui introduzida, entendemos que estas atribuições poderiam estar relacionadas com o que o autor argumenta sobre as "experimentações exploratórias" (SCHÖN, 2000). Neste caso específico, a experimentação não possui uma intencionalidade clara, o objetivo torna-se obter uma impressão das coisas, bem como "agir para ver o que deriva da ação". Estes conceitos interligados parecem induzir uma discussão mais profunda acerca dos materiais, pois sugerem a experimentação como uma dinâmica favorável a novas descobertas e interpretações. Além disso, os designers que se concentram na inovação orientada a materiais "[...] provavelmente usam uma abordagem experimental para projetar e incorporar novos materiais, ou reinterpretar o convencional" (PARISI; ROGNOLI e SONNEVELD, 2017, p.1168) .

A partir disto, o presente estudo visa relacionar tais perspectivas partindo do conceito da experimentação exploratória proposto por Schön (2000), como um processo projetual fundamentado e aparentemente próximo da ideia de "fluxo material" defendida por Ingold (2015). Por fim, será apresentado um experimento prático com materiais, a fim de melhor ilustrar estes pontos convergentes.

\section{Experimentação Exploratória}

No estudo sobre a inconsistência das dinâmicas educacionais e acadêmicas para com as suas aplicações práticas, Donald Schön na obra "Educando o Profissional Reflexivo" (SCHÖN, 2000) afirma o desafio de reconsiderar a formação profissional, uma vez que, tendo os seus princípios

\footnotetext{
1 Para Aristóteles qualquer coisa é composta de matéria (hyle) e forma (morphe), reunidos no ato da criação. O fazer começa com uma forma em mente e um pedaço sem forma de matéria-prima, e termina quando ambos estão unidos no artefato completo.
} 
governados por uma racionalidade técnica e científica, corresponde a um modelo que não considera a complexidade inerente do contexto. Seu discurso parte do pressuposto de que as práticas profissionais e suas capacidades resolutivas, estavam - conforme o período do estudo - sendo cada vez mais conflitadas por problemas únicos e indeterminados, que desafiam a ordem de soluções técnicas baseadas unicamente em pesquisas e teorias. Estas portanto, incapacitavam o aluno de desenvolver estratégias e raciocínios próprios durante e após o percurso de aprendizagem, repercutindo no que o autor considera como a "crise de confiança na educação profissional" (SCHÖN, 2000, p.15).

Entretanto, mediante a estes estudos, Schön (2000) se depara com as práticas de ateliê em arquitetura, onde identifica que o processo de aprendizagem é basicamente construído a partir de dinâmicas experimentais, através do fazer e da instrução. Estas práticas evidenciam-se pela capacidade de despertar qualidades subjetivas e inatas do operador, que condicionam um tipo de conhecimento relacionado ao nível tácito, respondendo direta e inconscientemente à ação. $\mathrm{O}$ autor referencia tal efeito como "talento artístico" e nos indica que esta capacidade também promove a maneira como aprendemos novas habilidades perante situações desconhecidas. Este processo de conhecer-na-ação, como bem comenta, é realizado perante atividades ditas "inteligentes", em que nossas performances num primeiro momento - tornam-se reflexos de constantes correções, reformulações e adaptações (SCHÖN, 2000) .

Na medida em que estas situações únicas passam a não corresponder com nossos esforços e expectativas, ou melhor, quando o problema se apresenta majoritariamente complexo, surpresas são desencadeadas. Desagradáveis ou não, sugerem um raciocínio crítico e simultâneo ao ato do fazer. Atingimos aqui um dos conceitos centrais da obra de Donald Schön, a "reflexão-na-ação". Enquanto processo reflexivo, este capacita reestruturar as estratégias de desenvolvimento de um projeto, as compreensões dos fenômenos, as formas de conceber os problemas e o experimento direto para a averiguação de hipóteses observadas (SCHÖN, 2000).

Vale elencar que o próprio conceito de estratégia dentro dos domínios de design pode compreender uma ação que não é predeterminada, mas que se utiliza das incertezas do contexto para idealizar novos cenários de ação. No processo de fazer, toda a ação proporciona uma forma qualquer de reação, que depende exclusivamente dos agentes envolvidos, assim como, das características do ambiente (Zurlo, 2010).

Para todas estas variáveis, a experimentação é o alicerce da conversação direta entre o operador (projetista) e a situação única. A lógica experimental portanto, acompanha todo o percurso da aprendizagem prática e reflexiva defendida na obra de Donald Schön. As experimentações consideradas neste caso, se afastam dos modelos científicos clássicos. No contexto prático em que se situam, suas variáveis relevantes tornam-se indeterminadas, pois modificam-se rapidamente pelos efeitos do ambiente, e por isso não devem ser previamente sustentadas por teorias duras e inalteráveis. $\mathrm{O}$ teste de hipóteses que surgem da ação imediata no entanto, assume uma conotação exploratória, sendo apenas um entre os vários tipos de experimentações existentes. No caso da prática, todas elas estão misturadas.

Nosso foco aprecia a experimentação que ocorre apenas para "ver o que deriva da ação" (SCHÖN, 2000, p.64 ), sem que acompanhe previsões ou expectativas por parte da pessoa envolvida. A este procedimento o autor compreende como experimentação exploratória:

Isso é o que uma criança faz ao explorar o mundo à sua volta, o que faz um artista ao justapor cores para ver o efeito que elas produzem e o que uma pessoa faz quando simplesmente caminha por um bairro para onde acaba de mudar-se. É também o que um cientista muitas vezes faz quando encontra e investiga uma substância estranha para ver como ela irá responder. O experimento exploratório é a atividade investigativa e lúdica, pela qual somos capazes de obter uma impressão das coisas. Ela é bemsucedida quando leva a alguma descoberta (SCHÖN, 2000, p.64).

Esta passagem deixa subentendido alguns aspectos relevantes para a discussão que aqui estamos construindo. Primeiro, a ideia de mudar alguma condição existente sem partir de intenções antecipadas. Entretanto, este processo de "vagueio" parece conduzir uma noção de experimentação do presente, ou seja, perceber um "todo" que está envolvido na situação. O simples fato de "caminhar sem direção em um bairro desconhecido", pode nos proporcionar algo além da descoberta de novos 
caminhos. Junto a isto, pode também nos situar como participantes da paisagem em que estamos imersos. É nesse momento em que absorvemos e somos transformados pelo "agora", onde mente e corpo diluem-se no ambiente e vão de encontro ao imprevisível.

Poderíamos lançar ainda em questão: como a nossa percepção sensorial e seu impacto na construção do nosso imaginário criativo revela-se durante o momento da exploração? De acordo com Franklin (2005), o físico George Darwin (filho de Charles Darwin), teria dito que "[...] de vez em quando, dever-se-ia realizar um experimento maluco, como tocar trombeta com tulipas todas as manhãs". Era provável que nada acontecesse, mas caso contrário, seria um grande avanço (Franklin, 2005, apud Hacking, 1983). Por mais absurdo que pareça, este aspecto lúdico da experimentação aparenta ser um ótimo estimulante para se "acatar o impossível". Isto portanto, pode ser um desafio para o experimentador, ao mesmo tempo em que a "verdade daquilo que se descobre" torna-se um desafio para a experimentação exploratória.

Resgatando brevemente nossa temática dos materiais enquanto matérias ativas e não permanentes (INGOLD, 2015), compreende-se que a ideia por trás desta prática de experimentação sugere um campo amplo de possibilidades e descobertas. Será com base nesta lente, que avançaremos para uma distinta visão sobre os materiais. Indo de encontro a um lugar em que as substâncias estão vivas e em constante sinergia com o meio circundante.

\section{Materialidade pela perspectiva de Tim Ingold}

Tradicionalmente, existe uma separação entre o mundo das ideias e o mundo material. Nesta visão, viveríamos em um cenário "platoniano", das cavernas e sombras. O material sob tal abordagem tornase um meio, algo que interliga dois fenômenos previamente alheios: a ideia e o artefato final.

A ponte de ligação entre a ideia e a produção é o material, que deve ser selecionado e processado até a reprodução física da ideia na forma de produto, levando em consideração as mais diversas condições de uso que o material precisa prever e atender (CALEGARI, OLIVEIRA, 2013, p.56, apud FERRANTE, WALTER, 2010).

O termo "ponte de ligação" citado pelos autores, sugere um afastamento entre aquilo que ocorre na mente criativa e aquilo que acontece no processo de criação, que é então preenchido pelo material neste espaço intermediário, aparentemente limitado e linear. Os termos "prever e atender" parecem sugerir que o material é selecionado de acordo com propriedades técnicas e reconhecidas pelo parâmetro da usabilidade, ditando uma participação reduzida e específica dentro dos modelos de produção.

Para Ingold (2015) este caráter hilemórfico que separa a forma da matéria ou ideia de artefato, assemelha-se ao conceito inapropriado de materialidade dentro dos campos da antropologia. Segundo o autor, as literaturas que abordam este assunto não estão próximas realmente dos materiais, mas sim de reflexões abstratas de filósofos e teoristas que, tratando de conceitos insondáveis como "agência, intencionalidade, funcionalidade, espacialidade, semiose, espiritualidade e encarnação" (ibidem, p.50), distorcem qualquer explicação compreensível do que é de fato a materialidade, os materiais e suas propriedades. Do pretexto de que na antropologia a natureza prática é o verdadeiro caminho para o conhecimento, surge o paradoxo de que a materialidade tem muito mais a dizer sobre os objetos já construídos e seus significados, do que a matéria enquanto ativa no ato do fazer. Os materiais então, ao que sustenta Ingold (2015), parecem estar desaparecidos.

$\mathrm{O}$ argumento de fundo para esta declaração, reflete mais uma vez a excessiva polarização da mente e da matéria, que levou gerações de teóricos em diferentes áreas, a crerem que a substância material do mundo se apresenta à humanidade como uma "lousa em branco", ou seja, uma dimensão inerte para a inscrição deliberada de formas ideacionais. Este modo de pensar, além de caracterizar uma separação metafísica entre mente e matéria, retrata uma concepção de realidade que também tem a separação como princípio, e portanto formadora do mundo. Para Christopher Gosden (1999, apud INGOLD, 2015), o mundo material pode ser dividido em dois amplos componentes: paisagem e artefatos. Nesse sentido temos a mente humana de um lado e um mundo material de paisagens e 
artefatos de outro. Bastaria isso para fundamentar uma compreensão heurística do que é o mundo e o que é material?

Segundo Ingold (2015), esta pergunta presume uma série de outros questionamentos, dos quais nos aproximam um pouco mais de seu pensamento acerca do assunto. Para o autor, poderíamos ainda indagar:

Começando pela paisagem, será que ela inclui o céu? Onde colocamos o sol, a lua e as estrelas? Podemos alcançar as estrelas, mas não podemos tocá-las: Será que elas são, então, realidades materiais com as quais os seres humanos podem fazer contato, ou será que elas existem para nós apenas na mente? [...] E quanto a luz do sol? A vida depende dela. Mas se a luz solar fosse um constituinte do mundo material, então teríamos de admitir não apenas que a paisagem diurna difere materialmente da noturna, mas também que a sombra de uma característica da paisagem, como uma rocha ou uma árvore, participa do mundo material tanto quanto a própria característica.

[...] Como engenheiros e construtores sabem todos muito bem, chuva e geada podem romper com estradas e edifícios. Como então podemos afirmar que estradas e edifícios sejam parte do mundo material, se a chuva e a geada não o são? (INGOLD, 2015, p.52).

Reflexões como estas rompem as nossas compreensões mais básicas sobre a matéria em relação a artificialidade. Para o autor, há uma discrepância no fato de que - na maioria das vezes tendemos a achar que o mundo material deveria apenas incluir coisas já transformadas pela atividade humana. Em um rápido experimento realizado em sala de aula, Ingold (2015) afirma que na tentativa dos alunos distinguirem objetos naturais e artificiais entre duas pilhas de objetos, elementos como a pedra, por exemplo, passam despercebidos sobre uma interpretação comum de matéria. No entanto, uma réplica de machado de caça primitivo encontrado por um dos alunos, parece evidenciar muito mais a presença material do que elementos propriamente "não transformados". A materialidade por fim, tal como evidencia Ingold (2012), parece conduzir a dois conceitos distintos. Primeiro a materialidade bruta, referente ao "caráter material" do mundo, em que a pedra (utilizando-se do exemplo anterior), é considerada simplesmente como uma massa sem forma de matéria.

Posteriormente, temos a fisicalidade do mundo material que oferece possibilidades para o agente humano. Neste caso, a materialidade se refere à "[...] agência social e historicamente situada dos seres humanos que, ao se apropriar dessa fisicalidade para seus propósitos, projetam nela o design e o significado na conversão de dada matéria-prima nas formas acabadas de artefatos" (INGOLD, 2012, p.432). A esta noção dúbia de materialidade, surge uma relação em que a cultura fornece as formas, a natureza os materiais, e dessa sobreposição, os humanos criam sua cultura material de contínua expansão.

De acordo com Deleuze \& Guattari (2004), é como se este modelo forma-matéria pudesse apenas confirmar as extremidades de duas meias-cadeias, e não o que as une de fato. Nesse processo simplificado de modelagem, o criador ou projetista encontra-se distante da real relação, fluida e variável, que ocorre entre a atividade de tomada de forma, no "devir das coisas". Para estes autores, o grande problema é que tal modelo "[...] ao assumir uma forma fixa e uma questão considerada homogênea, deixa de reconhecer por um lado, a variabilidade da matéria - suas tensões e elasticidades, linhas de fluxos e resistências - e por outro lado, as conformações e deformações às quais estas modulações dão origem" (ibidem, p.451).

Um exemplo clássico da "matéria em variação" por estes autores, se dá nos processos da metalurgia. Diferente de como normalmente é especificado este procedimento, a partir de etapas lineares e bem delimitadas, o material neste caso é quem realmente define a dinâmica processual. Assim, quando o ferreiro dá forma ao ferro pelo uso do martelo e da bigorna, ele precisa constantemente devolver a matéria ao fogo, ou seja, a variação material transborda para o processo formativo, e de fato, continua além dele. O ferro, por ora incandescente, emana diferentes respostas durante o trabalho, das quais o ferreiro - sob uma "dança gestual" contínua - deve seguir, até que o material esfrie e se torne rígido, determinando assim a finalização ou o avanço para um novo ciclo produtivo. 
A "ponte de ligação" entre a ideia e a produção, tal qual mencionamos no início deste capítulo, talvez possa ser agora desconstruída. Deste espaço unidirecional que fora uma vez atribuído ao processo de criação, transpassa uma "correnteza" que, sem limites ou direção, devolve aos materiais a sua vida.

\subsection{Matéria em fluxo}

Ao que caracteriza a contraposição do trabalho de Ingold sobre este modelo hilemórfico, estaria também a compreensão de um "mundo real dos materiais", em que estas separações entre meios - em especial forma e matéria - dão lugar a um único, porém extenso "oceano de materiais" (INGOLD, 2015).

o que este oceano revela para nós não é a homogeneidade branda de diferentes tons de matéria, mas um fluxo no qual materiais de todos os tipos, através de processos de mistura e destilação, de coagulação e dispersão, e de evaporação e precipitação, sofrem contínua geração e transformação" (ibidem, p.56).

As formas das coisas portanto, não se resumem a uma imposição externa sobre algum substrato inerte, mas emergem e são suportadas dentro deste fluxo material. Trata-se de um processo em que a matéria e as forças do ambiente se correspondem simultaneamente, e a forma por fim, representa o congelamento efêmero de um movimento generativo.

O pintor Paul Klee pode melhor esclarecer este argumento quando propõe que, os processos de ontogênese e crescimento que dão origem às formas que encontramos no mundo, são mais importantes que as próprias formas. Para este artista, forma é "o fim e a morte", enquanto o dar forma é "vida, movimento e ação" (KLEE, 1973, p.269, apud INGOLD, 2012). Sobre esta reflexão, novamente Deleuze \& Guattari (2004) comentam que em um mundo onde há vida, a relação essencial não se dá entre matéria e forma, substâncias e atributos, mas entre materiais e forças. Trata-se de como os diferentes tipos de matéria - com propriedades variadas - são avivadas pelo universo, misturadas e fundidas umas às outras na geração de "coisas".

No "real mundo dos materiais", do qual Ingold se refere como $\mathrm{ASO}^{2}$, seguir os fluxos materiais é definitivamente imaginá-los em um mundo em constante fervura. Para isso, bastaria pensar numa enorme cozinha, onde coisas são misturadas em combinações variadas, resultando em novos materiais que serão, por sua vez, misturados a outros ingredientes num processo de transformação sem fim (INGOLD, 2012). Para se "cozinhar" então, não devemos seguir uma receita, e sim:

Abrir recipientes e retirar seus conteúdos. Temos que destampar coisas. Em face das proclividades anárquicas de seus materiais, o cozinheiro ou cozinheira tem que se esforçar para manter alguma aparência de controle sobre o que se passa (INGOLD, 2012, p.25).

Por esta metáfora, certamente compreendemos que os humanos desempenham um papel nas transformações dos materiais. Talvez ainda, por uma perspectiva em que o processo seja dotado de pouco controle, e por isso, análogo à experimentação exploratória que bem discutimos anteriormente. Schön (2000) afirma que as intervenções - nem sempre propositais - durante o experimento, geram respostas inesperadas que levam a uma apreciação das coisas no momento da situação, ultrapassando percepções iniciais e permitindo novas descobertas.

Para tanto, Ingold (2012) nos aconselha que para entender os materiais e seguí-los em seus fluxos, devemos esquecer os conceitos básico da química, e sim, lembrar de como os materiais eram percebidos na Era da Alquimia, mais ou menos entre os séculos V e XVI. Como a "ciência" da Idade Média, a alquimia é a antiga maneira de lidar com os materiais, sem entender ao certo o que se passa com eles. Por meio dos experimentos alquímicos, muitos materiais foram obtidos a partir da combinação improvável de ingredientes, que provinham de uma variedade surpreendente de fontes.

\footnotetext{
2 Um mundo onde o "habitar" é se juntar aos processos de formação. Um lugar que não é composto por objetos estáticos e sim por "coisas" vivas, em constante transformação. Viver no ASO é viver em um mundo de matéria em fluxo.
} 
Entre os exemplos citados na obra de Ingold (2015), temos o material utilizado para trabalhos em estuque, na Inglaterra do século XVI. Segundo o relato, os ingredientes básicos da cal eram misturados com diversos materiais, sendo a maioria de origem animal: banha de porco, sangue de boi, esterco de vaca, erva-de-são-joão e ovos, erva-de-são-joão e cerveja, leite, glúten, manteiga, queijo, leite coalhado e cera saponificada.

A matéria por estas práticas, é percebida não pelo o que é, mas pelo o que faz, especificamente quando tratada de maneiras particulares. Descrevê-la é representar um enigma, cuja resposta só pode ser descoberta através da observação e do envolvimento com o que existe. O processo de criar portanto, acaba não sendo a imposição de forma à matéria, mas sim, a reunião de substratos diversos, combinando e redirecionando seus fluxos na tentativa de antecipar aquilo que irá emergir (INGOLD, 2012). O conhecimento construído por estes experimentos, não equivale à propriedades materiais objetivas e cientificamente mensuráveis. Trata-se de um saber que evolui durante uma vida de envolvimento com descobertas. Entender estas propriedades, segundo Ingold (2011, apud INGOLD, 2012), é poder contar as histórias dos materiais. Dizer o que fazem e o que lhes acontece quando explorados de maneiras peculiares, na própria prática de trabalhar com eles.

No ofício de um artista por exemplo, todos os seus gestos técnicos são uma pergunta do qual o material responde de acordo com sua inclinação. É ao seguir o fluxo de seus materiais, que os artistas interagem tanto quanto respondem com eles. A produção então, torna-se um processo de correspondência.

\section{Discussão a partir de uma experimentação exploratória com material}

A abordagem do presente estudo, procura relacionar as ideias defendidas por dois autores distintos, determinando a temática dos materiais como foco central de discussão para este fim. Partimos de uma breve contextualização do material e de sua participação em um nicho específico da área do design, como as práticas experimentais. Avançamos para a conceituação do que viria ser uma experimentação do tipo exploratória, a partir da ideia de "ensino prático reflexivo" defendida por Schön (2000). E por último, nos apropriamos das perspectivas do antropólogo Tim Ingold, a respeito de sua compreensão de material enquanto "matéria em fluxo" (INGOLD, 2015), para assim construir uma crítica a respeito de como a mesma é tratada dentro dos processos de criação.

Sobre o discorrer destas literaturas, alguns pontos convergentes puderam ser identificados entre as reflexões apresentadas. A fim de torná-los mais evidentes, utilizaremos de um caso prático que ilustra em grande parte estes fatores relacionais. O processo de experimentação que será apresentado, é um recorte do método Material Driven Design ${ }^{3}$, referente a sua etapa inicial de processo exploratório com materiais.

Apesar do método em sua epistemologia não atender exatamente às perspectivas defendidas por Ingold (2015), principalmente quanto à crítica feita ao modelo hilemórfico, pareceu pertinente utilizá-lo quando apenas em referência a esta fase primária, denominada "caracterização técnica" (KARANA et al., 2015). Nesta etapa, a experimentação Material Tinkering é sugerida como uma prática exploratória de mexer com os materiais sem ainda ter um projeto em mente (PARISI; ROGNOLI e SONNEVELD, 2017).

O designer é então encorajado a “[...] mexer com o material para cortá-lo, dobrá-lo, queimá-lo, combiná-lo com outros materiais, etc., para entender suas qualidades inerentes, suas restrições e oportunidades quando aplicado em produtos" (KARANA et al., 2015, p.12). Mediante estes procedimentos, o método prevê que o designer seja capaz de compreender as principais qualidades do material, principalmente em relação ao seu comportamento quando submetido a processos distintos de trabalho. Nesse sentido, o experimento parte da utilização de um único tipo de matéria. Em nosso caso, a escolha se deu pelo vidro.

\footnotetext{
3 Denominado de Material Driven Design (MDD) e desenvolvido por Karana et al. (2015), este método é adequado para quando o projeto determina um material específico como ponto de partida para o processo de design voltado à experiência. Como essência, o método considera as qualidades técnicas e experienciais do material em relação a forma como o mesmo pode ser percebido pelos usuários.
} 
Da mesma forma que este método (MDD) não apresenta um entendimento original do material para com a natureza de seus processos, a experimentação sugerida torna-se um tanto dispersa. Nesse quesito, eis uma riqueza de possibilidades, das quais o designer pode se valer da livre criatividade durante a dinâmica exploratória.

Nosso experimento partiu da trituração do vidro, até que o mesmo se reduzisse a pó. Este procedimento não surgiu de intenções prévias, mas sim, da curiosidade em entender o vidro quando em aspecto de areia, sua principal matéria-prima (sílica). Com a redução do material, iniciou-se uma interação que incitou algumas associações, tal como molhar o pó para obter uma massa compacta, semelhante a dos "castelos de areia" que costumávamos fazer na praia quando crianças.

Deste teste preliminar - já de caráter alquímico - se viu a possibilidade de utilizar tintas cerâmicas na mistura do vidro transparente com a água. Na medida que a tinta era adicionada e diluída na mistura, era possível obter diferentes tons de cores, que variavam de acordo com a quantidade de material e volume da água. A partir deste teste foi possível elaborar pequenas amostras que foram parcialmente fundidas em forno cerâmico, a fim de torná-las sólidas novamente após seu resfriamento. Este resultado é apresentado em sequência na figura 1 abaixo:

Figura 1 - Primeiro experimento com pó de vidro.
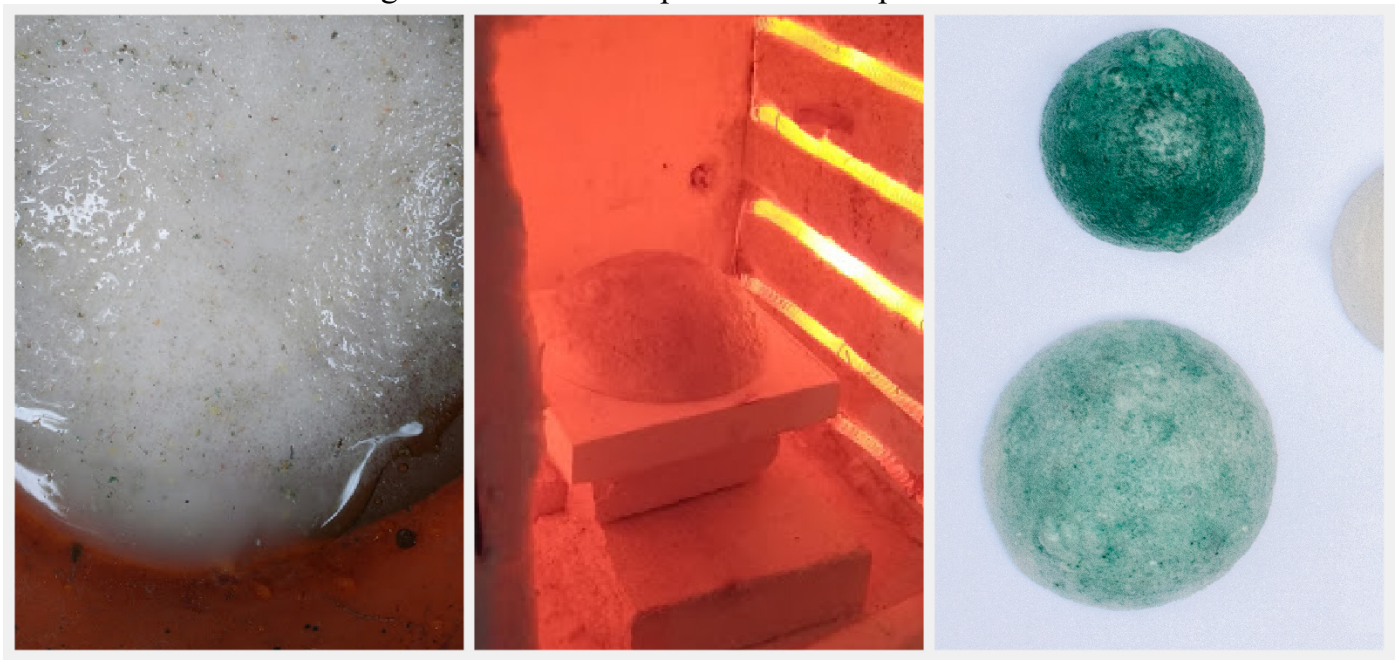

Fonte: Autores.

Outro experimento que ocorreu em paralelo, consistiu na fundição de um pó de vidro diferente ${ }^{4}$, sobre um molde cerâmico elaborado com a textura de elementos naturais. Note que a partir do primeiro envolvimento, algumas ideias de possíveis processos e formatos foram sendo idealizadas pelos autores, inevitavelmente. No entanto, o que surgiu desta vez foi algo extremamente inesperado. Seguindo o impulso de se utilizar de um maçarico a gás para a fundição do pó de vidro (sobre o molde), o mesmo começou a reagir de maneira curiosa. Pela camada viscosa que emergia do material, surgiram pequenos sulcos - buracos - que passaram a interferir no modo como acontecia o derretimento do vidro.

Sem muito entender o que ali acontecia, observou-se que quanto mais calor era direcionado ao material por meio da chama do maçarico, maior se dava a expansão destes orifícios em sua superfície. Neste momento, tornou-se claro que a reação do material acontecia apenas na região em contato com o fogo, se tratando de uma combinação entre temperatura e pressão aplicada pela chama. Após um bom tempo nesta relação de correspondência entre a matéria e as condições específicas do processo, atingiu-se um estágio em que a transformação do vidro parecia perder intensidade. Os orifícios da superfície cessaram o movimento de expansão, o que mostrou a impossibilidade de maiores intervenções. Neste momento, optou-se por encerrar a dinâmica e observar o que havia acontecido.

\footnotetext{
${ }^{4}$ Utilizou-se do refugo de uma vidraria localizada em Garibaldi - RS.
} 
Importante ressaltar que este mesmo procedimento também considerou outros tipos de vidro, mas apenas este último teria revelado transformações dignas de maiores investigações. Por isso, repetiu-se o processo inúmeras vezes, a fim de compreender cada vez mais as "repostas" que estavam sendo fornecidas pelo material. $\mathrm{O}$ resultado do experimento é ilustrado em sequência na figura 2 abaixo:

Figura 2 - Segundo experimento com pó de vidro.

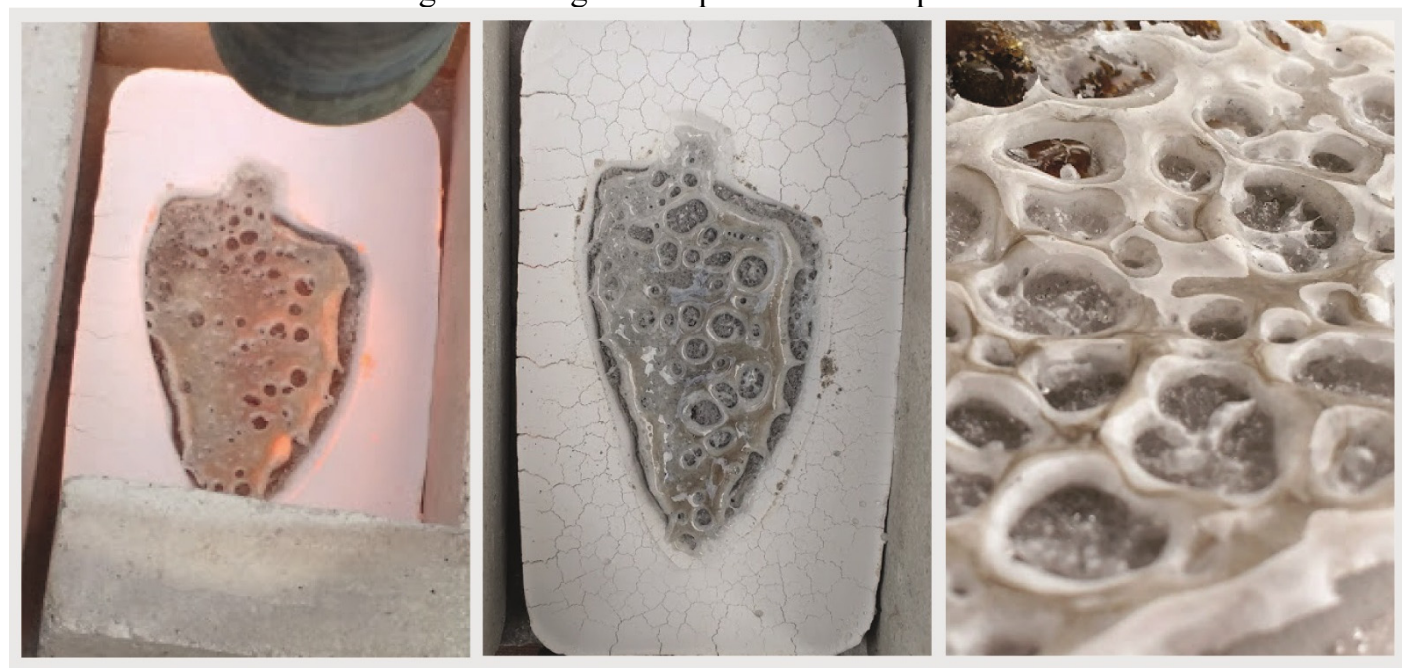

Fonte: Autores.

A reação inesperada que ocorrera, foi despertada por um processo de experimentação único, utilizando-se de recursos e condições de trabalho extremamente particulares (pó de refugo de vidro, molde de gesso, alta temperatura, ambiente aberto, etc.). O material vidro, que havia sofrido diversas transformações anteriores - até se tornar pó - possibilitou interações inusitadas. Com este processo de exploração, impressões foram obtidas, observações possibilitaram entender em parte o material, e com isso a necessidade de segui-lo para ver o que dele poderia emergir. Neste percurso de matéria em fluxo, revelou-se uma surpresa. Nada menos que a resposta de sua correspondência para com as forças do ambiente. Por meio dessa conversação ${ }^{5}$ (SCHÖN, 2000), direta e recíproca entre matéria, processo e operador, foi possível reconhecer as qualidades inerentes do material naquele momento, por aquela exata condição de trabalho.

Como resultado deste experimento, uma amostra vítrea totalmente atípica fora obtida. Ao analisar de perto, verificou-se algumas características interessantes, considerando que nenhuma interferência proposital tenha sido exercida para produzir os inúmeros efeitos encontrados. Sua coloração esbranquiçada (conforme figura 2) revela também alguns veios escuros, provenientes provavelmente da oxidação do vidro durante a fundição. A textura irregular da superfície é composta por uma "trama" de orifícios dos mais variados tamanhos, cuja aparência se assemelha a de um coral marinho. Estética que seria de improvável obtenção a partir dos processos comuns de produção industrial, uma vez que ocorrera do inesperado e não de procedimentos controlados ou mensuráveis.

Porém, não somente a isto se resume esta prática. A partir da experimentação exploratória com o vidro, se viu a relevância deste processo "hands on" ${ }^{6}$, em que a liberdade de interação com o material, compreendido para além do conceito hilemórfico, revela descobertas inimagináveis. Utilizar de métodos desta natureza não se trata de um retorno às práticas ancestrais de trabalho, mas sim, como ainda apontam Parisi, Rognoli e Sonneveld (2017), do avanço para a inovação, utilizando-se de um "driver" inspirador e criativo na qualificação do design.

\footnotetext{
${ }^{5}$ Schön salienta três dimensões para o processo de conversação reflexiva analisada em seu estudo de caso: "a linguagem nos quais o designer descreve e aprecia as consequências de suas ações, as implicações que ele descobre e segue, e suas mudanças de postura em relação à situação com a qual ele conversa" (SCHÖN, 2000, p.56).

${ }^{6}$ Refere-se à expressão "aprender fazendo".
} 
Destacamos que o caráter exploratório da dinâmica - de interação livre e espontânea conduziu uma atenção direta aos devires da situação, deixando de lado qualquer ideação de forma ou "coisa acabada". Desta imersão ao processo, foi possível despertar no material comportamentos até então desconhecidos pelos autores do experimento. Seriam propriedades que, como diria Ingold (2015), não podem ser consideradas como atributos fixos, mas sim processuais e relacionais.

$\mathrm{Na}$ tentativa de descrever aqui tais propriedades, se estaria - na verdade - contando uma história do material, do que acontece com ele quando flui, se mistura e se modifica (INGOLD, 2015). História que, na opinião dos presentes autores, deveria interessar os estudos em materiais e design.

\section{Conclusão}

O breve experimento apresentado, referente a etapa inicial de "caracterização técnica" pelo método Material Driven Design (KARANA et al., 2015), serviu para refletir sobre a relação das ideias que se julgaram correspondentes entre Schön (2000) e Ingold (2015). O método se mostrou como uma referência para se começar a conduzir um processo de experimentação exploratória com a utilização de um material.

Reforçamos então que, os conceitos trazidos por Schön (2000) como: a não intenção prévia para com o experimento exploratório, a imprevisibilidade da ação, a surpresa, o conhecimento-na-ação e até mesmo o talento artístico, parecem ser fatores que potencializam a experimentação com materiais quando estes também são entendidos como "matérias em fluxo" (INGOLD, 2015). Permitir esta leitura dos materiais, considerando a sua natureza generativa, repentina e correlata com o meio circundante, instiga um novo sentido para a experimentação exploratória em âmbito material, que não vê na forma final o único valor da matéria, mas na capacidade de corresponder constantemente com o universo, a sua manifestação de vida.

Muito provável que estas relações estejam sendo exercitadas na prática por uma grande quantia de designers entre outros profissionais. No entanto, nosso objetivo aqui se deu em identificar possíveis relações teóricas entre dois autores distintos, tendo a temática material como centralidade. Ainda que se tratando de uma simples contextualização, tais reflexões parecem interessar novas investigações. Por ora, acredita-se que este estudo possa induzir os leitores a buscarem novos conhecimentos a partir destes autores. E se possível, inspirar pequenas práticas experimentais com uso de materiais dentro do design.

\section{From the possible dialogue between Donald Schön and Tim Ingold to an experimental practice with material}

Abstract: This article aims to explore the possible relationship between Donald Schön's idea of exploratory experimentation and the understanding of material advocated by anthropologist Tim Ingold. Such concepts, when approached, seem to correspond to a deeper discussion about the material dimension in design, proposing paths of relational actions, and therefore, less concerned with scientific investigations. In order to investigate this potential, a short experiment by the authors was used, in an attempt to better illustrate the reflections brought by these approaches. Finally, it was found tha is possible to awaken unknown behaviors in the material, through a practice that proved to value the unpredictability of the creation process, as well as the impermanent character of the material, considered here "alive".

Keywords: materials; design; material experimentation 


\section{Referências bibliográficas}

CALEGARI, E; OLIVEIRA, B. Um estudo focado na relação entre design e materiais. Projética: Londrina, v.4, n.1, p. 49-64, Jan./Jun. 2013

DELEUZE, G; GUATTARI, F. A Thousand Plateaus: Capitalism and Schizophrenia. London: Continuum, 2004

DIAS, Maria Regina Álvares Correia. Percepção dos materiais pelos usuários: modelo de avaliação Permatus. Florianópolis: UFSC, 2009

FRANKLIN, L.R. Exploratory Experiments. Chicago: The University of Chicago Press, Philosophy of Science Association, p.888-899, 2015

GLOEDEN, D. A Ressignificação do Vidro pelo Design: Projeto de produto sob perspectivas do design para emoção e da experiência material. Novo Hamburgo: Feevale, 2019

INGOLD, T. Toward an Ecology of Materials. Annu. Rev. Anthropol. 41:427-42, 2012

INGOLD, T. Estar Vivo: Ensaios sobre movimento, conhecimento e descrição. Petrópolis: Editora Vozes, 2015

KARANA, Elvin et al.. Material Driven Design (MDD): A Method to Design for Material Experiences. Internation Journal of Design, 9 (2), p.35-54, 2015

MANZINI, E. A Matéria da Invenção. Lisboa: Centro Português de Design, 1993

PARISI, Stefano; ROGNOLI, Valentina; SONNEVELD, Marieke. Material Tinkering: An inspirational approach for experiential learning and envisioning in product design education. The Design Journal, 20:Sup1, S1167-S1184, 2017

SCHÖN, D. Educando o Profissional Reflexivo: um novo design para o ensino e a aprendizagem. Trad.Roberto Cataldo Costa. Porto Alegre: Artmed, 2000

ZURLO, Francesco. Design Strategico. In: XXI Secolo, vol. IV, Gli spazi e le arti. Roma: Enciclopedia Treccani, 2010 